\title{
Decade Review (1999-2009): Artificial Intelligence Techniques in Student Modeling
}

\author{
Athanasios S. Drigas, Katerina Argyri, and John Vrettaros \\ NCSR DEMOKRITOS, \\ Institute of Informatics and Telecommunications \\ Net Media Lab \\ Ag. Paraskevi, 15310, Athens, Greece \\ \{dr,jvr\}@iit.demokritos.gr, akate82@gmail.com
}

\begin{abstract}
Artificial Intelligence applications in educational field are getting more and more popular during the last decade (1999-2009) and that is why much relevant research has been conducted. In this paper, we present the most interesting attempts to apply artificial intelligence methods such as fuzzy logic, neural networks, genetic programming and hybrid approaches such as neuro fuzzy systems and genetic programming neural networks (GPNN) in student modeling. This latest research trend is a part of every Intelligent Tutoring System and aims at generating and updating a student model in order to modify learning content to fit individual needs or to provide reliable assessment and feedback to student's answers. In this paper, we make a brief presentation of methods used to point out their qualities and then we attempt a navigation to the most representative studies sought in the decade of our interest after classifying them according to the principal aim they attempted to serve.
\end{abstract}

Keywords: student modeling, student diagnosis, fuzzy logic, neural networks, genetic programming, student assessment, student evaluation, adaptive learning.

\section{Introduction}

Traditionally artificial intelligence aims at simulating filtering information, handling constraints, recognizing patterns and making logical inferences as well as other activities necessary in order to deal with real - life problems in an automated way. In the last decades, each and every one of the activities mentioned above, have been a real challenge, as the researchers' community realized that they are of significant practical value for learning sciences especially when seeking to obtain in an automatic way active and reflective learning just like all learning theories suggest.

Artificial intelligence has a wide range of applications in the educational field and new directions are constantly given in educational research. Among the most typical of them are several areas such as intelligent information retrieval [11], natural language processing in order to accomplish tasks such as evaluation of student's work [13], intelligent agents [25] (in the wider field of expert systems [40]), robotics [26], intelligent virtual environments [10], voice and image recognition [31] especially used for data input in cases of learning or physical impairments and e-tutoring [1]. 
In this paper, we will focus on the techniques incorporated during last decade (1999-2009) and on student modeling as it seems to be one of the latest research trends and in the same time one of the most significant and challenging tasks for an instructor, let alone for an intelligent tutoring system.

According to Stathakopoulou et al. (2005), student modeling is consisted of two components: the student model and the diagnostic module [2]. The student model is one of the components of an Intelligent Tutoring System which provides a description of student related information such as his knowledge level, skills or even preferences while diagnosis is the inference process which in the end updates the student model.

Eklund and Brusilovsky (1998) suggest that the student model keeps track of students' state of mind on the basis of their responses [27]. Consequently, reliable student modeling comes up via careful student assessment, the process that allows the expert to diagnose the learner's mental state and knowledge status in order to check on the efficiency of teaching and to detect possible learning deficiencies.

The idea of the creation of a student model via an automated way is a realistic and hopeful one since according to Frias - Martinez et al. [21], a user (in the more generalized user modelling problem) leaves trail while using a hypermedia system and these data can be stored and used in order to generate further information, patterns and predictions.

The popularity of this task is more than justified if one takes into consideration the fact that "student model enables these systems (adaptive and intelligent web-based Educational Systems) provide individualized course content and study support to help students with different background and knowledge status to achieve their learning objectives" [15]. After all, high adaptability in teaching, a goal strongly connected with student diagnosis, has proved to be a fruitful way to maximize learning results [22]. Indeed, studies sought have shown that students process knowledge and learn in different ways and that is why researchers strongly believe that students learn in an efficient way when teaching is tailored according to their personal learning style and other individual characteristics [40].

In this context many artificial intelligence techniques keep on triggering researchers' attention and their incorporation in more and more aspects of the educational field is being adopted.

To name just a few, neural networks, Bayesian networks, Markov models, control theory, fuzzy logic as well as search methods such as genetic and evolutionary algorithms are used to serve this purpose, alone, in all possible combinations among them, or in combination with different techniques, such as other machine learning algorithms for more efficiency.

\section{Artificial Intelligence in Student Modeling}

As it was mentioned above, student modeling has been a real challenge for researchers in the educational field especially over the last decade. But in order for that to be achieved, the knowledge as well as the experience of the educational expert has to be represented in a precise way and most important, the inference process used by the expert must be modelled and simulated [4].

The most useful tools for approaching those goals and finally obtaining reliable student diagnosis will be described in a few words and the qualities of each technique will be pointed out. 


\subsection{Artificial Intelligence Methods Used}

Artificial Neural Networks (ANN) are computational models, inspired by the way biological neurons process information. These decision - making tools are weighted interconnected networks of artificial neurons and have the ability of "learning" through experience via algorithms. Currently, neural networks become more and more popular in various scientific fields including the educational one. Just a few of their significant abilities are the fact that they recognize patterns, they derive meaning from vague data and not only they learn in an adaptive way, but they also identify matching in similar cases Stath [21]. In education the qualities of the neural networks are used in order to simulate and monitor a learner's cognitive progress [2], [9] and to obtain classification of students sharing common characteristics.

Fuzzy logic is a multi-valued version of Boolean logic based on fuzzy set theory. It was introduced (formally by Zadeh, who axiomatized fuzzy set theory in 1965 [10]) in order to handle uncertainty in everyday problems caused by imprecise and incomplete data, as well as human subjectivity. A fuzzy set is defined as an ordered set

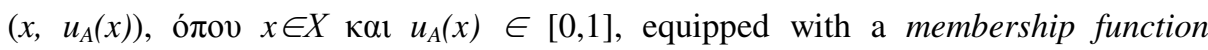
$\mu_{\mathrm{A}}(x): X \rightarrow[0,1], \quad$ where $\mu_{\mathrm{A}}(x)=\left\{\begin{array}{cc}1, & x \text { absolutely in } A \\ 0, & x \text { absolutely not in } A . \\ (0,1), & x \text { partially in } A\end{array}\right.$

Value $u_{A}(x)$ is called degree of membership or membership value. Consequently, one could say that Boolean logic is nothing but a generalization of fuzzy logic since both versions coincide when membership function is allowed to have only two possible values (0/1). Fuzzy logic is gaining more and more popularity (even in business world since already by middle nineties more than 6.1 billion dollars were gained in a year just in Japanese fuzzy logic industry) and according to Stathakopoulou et al. (2005) the application of fuzzy logic principles in student modeling is more than attractive since it overcomes computational complexity issues and thanks to its human-like nature is user and designer friendly [2]. In education, researchers try to take advantage of the way that fuzzy logic model human decision - making aiming to achieve diagnosis of a student's knowledge level [10], [11]. Hawkes et al. were among the first to adopt fuzzy student modeling [32].

Genetic programming is a search algorithm used to identify the most efficient candidates for a specific task via the creation of a computer program. It is based on biological evolution principles, namely the Darwinian survival of the fittest. The steps that a genetic algorithm follows are presented below:

- $\quad$ assess the initial population according to specified criteria,

- if a possible solution satisfies the criteria, stop, else,

- $\quad$ select the most satisfying candidate and reproduce (via crossover and mutation),

- $\quad$ return to the first step

In education, genetic algorithms are a valuable tool since they can be used to derive a reliable expert knowledge representation. 
Last but not least, many hybrid approaches are among the most popular choices of educational researchers since through research conducted so far, they have proved to deal better with complexity and vagueness issues. Among the most popular synergies are neuro - fuzzy systems and GPNN methodology. In the first case many problems coming up during separate use of the two technologies are being overcome since their combination offers a fuzzy inference system which uses a neural network learning process [24]. The latter approach, takes advantage of the fact that genetic algorithms can provide optimal network architectures [33]. In other words, genetic programming is applied on an initial population of neural networks in order to obtain an ideal one via reproduction, crossover and mutation.

\subsection{Literature Sources and Filtering Formulas}

During the last decades and especially in the last one, research of artificial intelligence in education has expanded in so many levels that it would be impossible for someone to study in detail all kinds of research achievements. Consequently, we chose to analyze a subset of all the papers examined, the one that covers issues useful in obtaining accurate and reliable student modeling. The papers we studied were included in research platforms such as ISI Web of Knowledge, database bibliography sites such as Digital Bibliography \& Library Project (DBLP) and Scopus as well as web search engines such as Google Scholar. The research was conducted combining the following keywords: student model, student modeling, student diagnosis, intelligent learning systems, intelligent tutoring systems, fuzzy logic, neural networks, genetic programming, neuro-fuzzy systems, learning styles, adaptive learning and assessment. So, after completing a detailed literature review and a filtering with respect to the publication year, the artificial intelligence methods used and the main relevant conferences and journals, we came up with the final selection of papers. In the end, we came to the conclusion that the most meaningful way to organize the research in the particular field is to categorize the studies conducted according to the purpose they attempted to serve. Equations should be punctuated in the same way as ordinary text but with a small space before the end punctuation mark.

\section{State of the Art}

First of all we need to observe that one common goal that the majority of papers under study shared was classification of the students, namely the attempt for every student to be mapped in one of several predefined groups. The classification purpose though was different from study to study. There were researchers that chose to achieve this categorization giving emphasis to the individual characteristics (such as learning style) of a student and so the enhancement of individualized learning was the actual goal. There where also researchers that gave emphasis to coming up with a reliable assessment method of students cognitive state some of them seeking to the traditional students' assessment and ordering and others to predict students' future performance or even to fix in time serious learning deficiencies. 


\subsection{Studies Classifying Students According to Their Knowledge Level / Modeling Their Future Performance}

Ma and Zhou (2000) implemented a fuzzy set approach in order to assess the outcomes of learning process. In this paper fuzzy set principles were applied to the determination of the assessment criteria and the corresponding weights and finally students' performance was evaluated on a fuzzy grading scale according to the selected criteria. The application of this method as well as the use of a group decision support system (GDSS [34]) was attempted in the Department of Information Systems at the City University of Hong Kong [35], [36]. With the help of a control group, experimental results have proved that this method empowers a deeper approach of learning [28].

Olds et al. (2000) have implemented a software package called Cogito aiming at accurate and inexpensive measurement of the students' ability to think critically acquired so far. Cogito makes use of a neural network in order to obtain pattern recognition in learners' data and finally matching with models of intellectual development that have come up via traditional interviews. Cogito keeps being developed, retraining the neural network with new data extracted from interviews on 60 additional subjects, updating its interface and forming extra partnerships with several institutions [8].

Weon \& Kim (2001) introduced a learning evaluation system aiming at providing more flexible results comparing to numerical results which come up applying traditional assessment methods. This approach makes use of fuzzy linguistic variables representing each question and then evaluates a score taking into account the membership degree of uncertainty factors. This method has been tested on $4^{\text {th }}$ grade students of an elementary school with promising results [12].

In 2004, Hammadi and Milne designed a student classification method using neurofuzzy techniques in order to obtain learners' performance prediction before admission to college. The learner's secondary school marks and his college entry test performance are the inputs of the neuro-fuzzy system. The system outputs the student's performance in the first semester of his college studies. This system, NEFCLASS, was proposed for pattern recognition and fuzzy data analysis. The system has been tested using actual student exam results and participants were classified into three categories according to the expected performance with encouraging results in most cases [14].

In the same year Vrettaros et al., developed a diagnostic system of taxonomies based on fuzzy logic which is mostly ideal for e - learning systems [41], [42]. The procedure described by the authors consists of an initial processing of the filled up questionnaires, students' categorization into level in five separate theme sections and students' categorization according to the given answers into one of the predefined knowledge levels. This system has been tested on 100 high school and senior high school students in mathematics and results were in significant accordance with cognitive science expert's results [9].

Nykanen (2006) introduced a fuzzy system aiming at predicting students' performance and finally preventing students from failing, dealing in time with serious learning deficiencies and giving extra assistance if needed. Experiments have been conducted using two data sets which describe students' performance in a university mathematics course in 2003 and 2004 at the Tampere University of Technology, Finland [20]. 


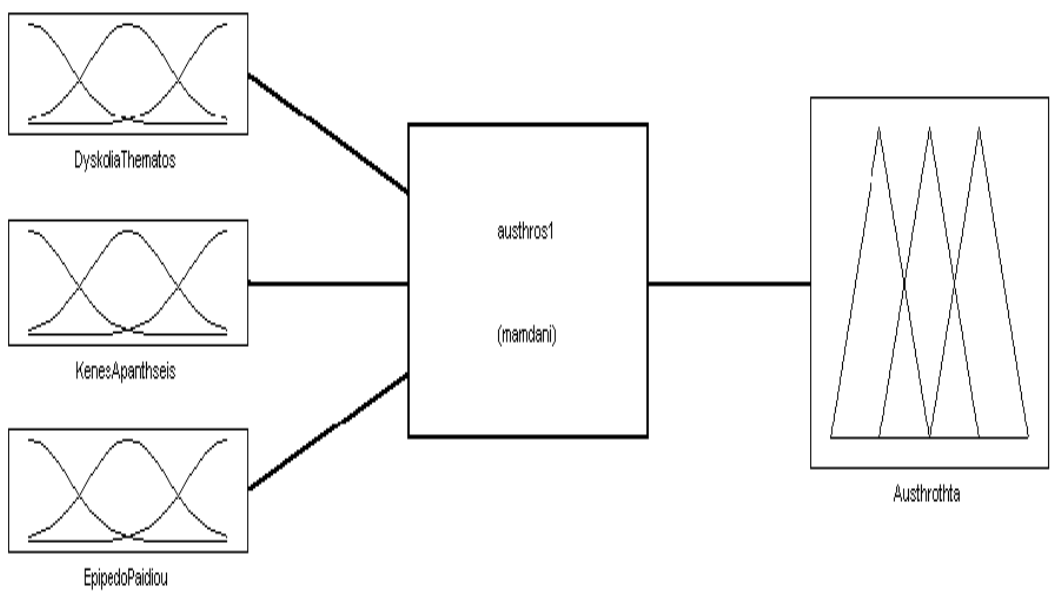

Fig. 1. Inputs and output of the system [9]

The System is being trained ower the data

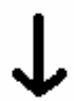

A number of appropriate Neural Networks is being resulted

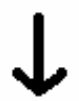

The leamer answers online the questionnaire

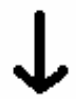

The learner's answers are being encoded and being used as input to the system

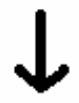

The trained Neural Networks output their result for the specific input.

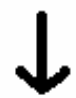

Af evaluati on through all the learrifig areas is being resulted

Fig. 2. The steps of the assessment system [1] 
Sevarac (2006) used a neuro-fuzzy reasoner (NFR) system ideal for e-learning applications performing student modelling in a flexible way since it can be tailored to the teacher's preferences. As an application, the author presents the use of the system for students' classification reasons according to the test results and the time of test completion. The classification rules were taken from a human expert and the predefined classes were bad, good, very good and excellent. The system went through an initial testing with very satisfying success rate and it was also successfully tested through an actual e- learning application called Multitutor [30].

In 2008, Vrettaros et al. tried to obtain learners' assessment evaluating their answers according to a number of examined criteria. The final aim was to equip the elearning platform with a reliable evaluation tool substituting an e-tutor. This was attempted with the implementation of a Neural Network Genetic Programming method. The GPNN system was trained through students' answers as well as the assessment given by an expert, and to be more specific, through actual data extracted from an educational project called DEDALOS. Genetic programming was incorporated in the neural network approach (as an alternative to a back propagation algorithm) for optimization reasons such as quick convergence to the solution [1].

In the same year, Wang and Chen [6] suggested a new way of evaluating students' answerscripts with the use of fuzzy numbers in combination with degrees of confidence of the evaluator and considering a degree of optimism for each evaluator to achieve flexibility. Nine satisfaction levels represented by triangular fuzzy numbers were used for students' classification. Experimental results indicated that the approach proposed in this paper is an intelligent and stable one comparing to older methods proposed [38], [39].

\subsection{Studies Inferring Individual Characteristics and Aiming at Adaptive Learning}

In 1999 Hwang came up with an intelligent computer- assisted testing and diagnostic system which empowered individualized learning as it had the ability of providing dynamic tests according to the learner's characteristics. This system is based on fuzzy reasoning principles and enhances the improvement of students' learning status. This is obtained giving the learner the choice to adjust the parameters according to which the test items differentiate, offering guidance after the learner has done the test as well as offering indications in case of learning deficiencies. The system consists of a student information database, an item bank, a Java - based interface, a testing and diagnostic unit as well as a fuzzy interface. For the evaluation of the instructing system a group of 30 students from a primary school was used with encouraging results [7].

Kinshuk et al. (2001) have used a fuzzy propagation approach which is based in a Neuro - Fuzzy system aiming at maximizing adaptability in business education tutoring. The student's data that come up during interaction are being input to the FBP in order for the network to be trained. The system described by the authors consists of the interactive mode where learning takes place and of the assignment mode where assessment of the student's success in the first mode takes place [3].

Shen et al. (2001) constructed an assessment system, part of a student oriented network system, ideal for web - based distance learning. It makes use of several artificial intelligence technologies such as neural networks, fuzzy set theory, genetic and back 
propagation algorithms in order to succeed not only in assessing and classifying students but also in constructing types of student profiles so as to empower the adaptability of the learning content to each individual's needs. Via those technologies the results are impressive even in cases where data is extremely vague and subjective [16].

Grigoriadou et al. (2002) have attempted to achieve precise student diagnosis incorporating fuzzy logic and multicriteria decision-making in INSPIRE (Intelligent System for Personalized Instruction in a Remote Environment), a web - based AEHS (Adaptive Educational Hypermedia System - Brusilovsky, [43]). Via this combination, enhancement of adaptability of INSPIRE is being achieved. The authors focus on student's diagnostic module which aims at student's classification according to his knowledge level and learning style. The method described has been tested over 20 postgraduate students of the Department of Informatics and Telecommunications of the University of Athens and proved to offer students' assessment as much reliable as the one performed by a human teacher [4].

In 2003, De Arriaga et al. created an ILS (Intelligent Learning System) based on multi - agent architectures. Via this system, using a fuzzy set for each individual and for each one of the basic learning styles, the determination of the learning style is obtained. Secondly, the student's knowledge level as well as the learning ability is being assessed and finally, the overall student grade comes up. This technique has already been used in TUTOR3 and according to the results, the assessment performed is reliable and the individualization of the learning process is enhanced [5].

Stathakopoulou et al. (2004) attempted to create and update a student model identifying students' individual characteristics. For this purpose, a neural network - based fuzzy model was implemented where the fuzzy component aimed at simulating human decision making and the neural networks were incorporated to provide it learning and generalization abilities. Neural networks were trained through actual students' profiles. The diagnosis that came up with the help of the model was compared to the one based on the judgement of a group of five teachers and the model proved to handle uncertainty in a smooth way even if we are dealing with marginal cases [2].

Mir Sadique \& Ghatol (2004), attempted to use the architecture of the Adaptive Neuro Fuzzy Inference System (ANFIS) in the field of Intelligent Tutoring Systems aiming at reliable and precise student modelling. According to the authors' description, learners are tested in concept understanding, memorizing skills and possible misconceptions and results of these tests are given as input in the inference system. Finally, learners' performance is categorized as poor, fair, good or excellent. This method has proved to give results matching to those that come up from human teachers' evaluation [29].

According to De Arriaga et al. (2005), FINANCE, a system for learning Financial Accounting and Business Analysis based on a fuzzy intelligent research system called NEOCAMPUS2, offers a full and reliable student model. According to experimental results with the necessary use of control groups, FINANCE turned out to be a fruitful way of learners' assessment especially comparing to the traditional evaluation methods. Most important of all, this method achieved significant acceleration of the novices' turning into experts (more than 25\% time needed for the control groups) [18].

Homsi et al. (2008) introduced an Adaptive and Intelligent Web - Based Educational System (AIWBES) which makes use of an algorithm based on Fuzzy - ART2 neural network and Hidden Markov Model (HMM), which is a stochastic method. 
Table 1. Papers' Categorization

\begin{tabular}{|c|c|c|c|c|}
\hline title & year & $\begin{array}{l}\text { individual } \\
\text { characteristics } \\
\text { /adaptive } \\
\text { learning } \\
\end{array}$ & $\begin{array}{l}\text { students' } \\
\text { classification } \\
\text { based on their } \\
\text { performance }\end{array}$ & $\begin{array}{l}\text { prediction of } \\
\text { students' } \\
\text { performance }\end{array}$ \\
\hline $\begin{array}{l}\text { Development of an } \\
\text { intelligent testing and } \\
\text { diagnostic system on } \\
\text { computer networks }\end{array}$ & 1999 & yes & - & - \\
\hline $\begin{array}{l}\text { Fuzzy set approach to } \\
\text { the assessment of student- } \\
\text { centered learning }\end{array}$ & 2000 & - & yes & - \\
\hline $\begin{array}{l}\text { Measuring the } \\
\text { intellectual development of } \\
\text { students using intelligent } \\
\text { assessment software }\end{array}$ & 2000 & - & yes & - \\
\hline $\begin{array}{l}\text { Learning achievement } \\
\text { evaluation strategy using } \\
\text { fuzzy membership function }\end{array}$ & 2001 & - & yes & - \\
\hline \begin{tabular}{l}
\multicolumn{1}{c}{ The intelligent } \\
assessment system in \\
web_based distance \\
learning education
\end{tabular} & 2001 & yes & yes & - \\
\hline $\begin{array}{l}\text { Adaptive tutoring in } \\
\text { business education using } \\
\text { fuzzy backpropagation } \\
\text { approach }\end{array}$ & 2001 & yes & - & - \\
\hline $\begin{array}{l}\quad \text { Fuzzy Inference for } \\
\text { student diagnosis in } \\
\text { Adaptive Educational } \\
\text { Hypermedia }\end{array}$ & 2002 & - & yes & - \\
\hline $\begin{array}{l}\quad \text { Fuzzy logic applications } \\
\text { to students' evaluation in } \\
\text { intelligent learning } \\
\text { systems. }\end{array}$ & 2003 & yes & yes & yes \\
\hline $\begin{array}{l}\text { A neuro - fuzzy } \\
\text { classification approach to } \\
\text { the assessment of student } \\
\text { performance }\end{array}$ & 2004 & - & - & yes \\
\hline $\begin{array}{l}\text { A neuro - fuzzy } \\
\text { classification approach to } \\
\text { the assessment of student } \\
\text { performance. }\end{array}$ & 2004 & - & yes & yes \\
\hline $\begin{array}{l}\text { Development of a } \\
\text { diagnostic system of } \\
\text { taxonomies using fuzzy } \\
\text { logic-case SOLO (useful } \\
\text { for e-learning system) }\end{array}$ & 2004 & - & yes & - \\
\hline
\end{tabular}


Table 1. (continued)

\begin{tabular}{|c|c|c|c|c|}
\hline $\begin{array}{l}\quad \text { A Neuro Fuzzy } \\
\text { Inference System For } \\
\text { Student Modeling In Web- } \\
\text { Based Intelligent Tutoring } \\
\text { Systems }\end{array}$ & 2004 & yes & yes & - \\
\hline $\begin{array}{l}\quad \text { Neuro -Fuzzy } \\
\text { knowledge processing in } \\
\text { intelligent learning } \\
\text { environments for improved } \\
\text { student diagnosis }\end{array}$ & 2005 & yes & - & - \\
\hline $\begin{array}{l}\text { Evaluation of fuzzy } \\
\text { Intelligent Learning } \\
\text { Systems }\end{array}$ & 2005 & yes & yes & yes \\
\hline $\begin{array}{l}\text { Neuro Fuzzy Reasoner } \\
\text { for Student Modeling }\end{array}$ & 2006 & - & yes & - \\
\hline $\begin{array}{l}\text { Inducing Fuzzy models } \\
\text { for student classification }\end{array}$ & 2006 & - & yes & yes \\
\hline $\begin{array}{l}\text { The development of a } \\
\text { self-assessment system for } \\
\text { the learners answers with } \\
\text { the use of GPNN }\end{array}$ & 2008 & - & yes & - \\
\hline $\begin{array}{c}\text { Student modeling using } \\
N N-H M M \text { for EFL course }\end{array}$ & 2008 & yes & yes & - \\
\hline \begin{tabular}{l}
\multicolumn{1}{c}{ Evaluating Students' } \\
Answerscripts Using Fuzzy \\
Numbers Associated With \\
Degrees of Confidence
\end{tabular} & 2008 & - & yes & - \\
\hline
\end{tabular}

Reliable student modelling is attempted through two stages, the initializing where personal and educational information is gathered and the updating one which updates the knowledge status. The goal of this system is assessing learners taking into consideration five parameters and determining their knowledge level in order to categorize them in six levels. This study attempted a hybrid approach combining a machine learning algorithm with a soft computing synergy and according to experimental results, the combination which was used achieved a precise learners' categorization [15].

The online version of the volume will be available in LNCS Online. Members of institutes subscribing to the Lecture Notes in Computer Science series have access to all the pdfs of all the online publications. Non-subscribers can only read as far as the abstracts. If they try to go beyond this point, they are automatically asked, whether they would like to order the pdf, and are given instructions as to how to do so.

Please note that, if your email address is given in your paper, it will also be included in the metadata of the online version.

The correct BibTeX entries for the Lecture Notes in Computer Science volumes can be found at the following Website shortly after the publication of the book: http://www.informatik.uni-trier.de/ ley/db/journals/lncs.html 


\section{Conclusions}

In order to permit cross referencing within LNCS-Online, and eventually between different publishers and their online databases, LNCS will, from now on, be standardizing the format of the references. This new feature will increase the visibility of publications and facilitate academic research considerably. Please base your references on the examples below. References that don't adhere to this style will be reformatted by Springer. You should therefore check your references thoroughly when you receive the final pdf of your paper. The reference section must be complete. You may not omit references. Instructions as to where to find a fuller version of the references are not permissible.

We only accept references written using the latin alphabet. If the title of the book you are referring to is in Russian or Chinese, then please write (in Russian) or (in Chinese) at the end of the transcript or translation of the title.

The following section shows a sample reference list with entries for journal articles [1], an LNCS chapter [2], a book [3], proceedings without editors [4] and [5], as well as a URL [6]. Please note that proceedings published in LNCS are not cited with their full titles, but with their acronyms!

Acknowledgments. The heading should be treated as a $3^{\text {rd }}$ level heading and should not be assigned a number.

\section{References}

1. Vrettaros, J., Pavlopoulos, J., Vouros, G.A., Drigas, A.: The Development of a Selfassessment System for the Learners Answers with the Use of GPNN. In: Lytras, M.D., Carroll, J.M., Damiani, E., Tennyson, R.D. (eds.) WSKS 2008. LNCS (LNAI), vol. 5288, pp. 332-340. Springer, Heidelberg (2008)

2. Stathakopoulou, R., Magoulas, G., Grigoriadou, M., Samarakou, M.: Neuro -Fuzzy knowledge processing in intelligent learning environments for improved student diagnosis. Information Sciences 170, 273-307 (2005)

3. Kinshuk, A., Nikov, A., Patel, A.: Adaptive Tutoring in Business Education Using Fuzzy Backpropagation Approach. In: Proceedings of the Ninth International Conference on Human-Computer Interaction, pp. 465-468 (2001)

4. Grigoriadou, M., Kornilakis, H., Papanikolaou, K., Magoulas, G.: Fuzzy Inference for Student Diagnosis in Adaptive Educational Systems. In: Vlahavas, I.P., Spyropoulos, C.D. (eds.) SETN 2002. LNCS (LNAI), vol. 2308, pp. 191-202. Springer, Heidelberg (2002)

5. de Arriaga, F., Arriaga, A., El Alami, M., Laureano-Cruces, A., Ramírez-Rodríguez, J.: Fuzzy Logic Applications To Students' Evaluation in Intelligent Learning Systems. In: En Memorias XVI Congreso Nacional y II Congreso Internacional de Informática y Computación de la ANIEI, Zacatecas, 22-24 de octubre del, vol. I, pp. 161-166 (2003)

6. Hui-Yu, W., Shyi-Ming, C.: Evaluating Students' Answerscripts Using Fuzzy Numbers Associated With Degrees of Confidence. IEEE Transactions on Fuzzy Systems 16(2) (April 2008)

7. Hwang, G.J.: Development of an intelligent testing and diagnostic system on computer networks. In: Proceedings of the National Science Council of ROC, vol. 9(1), pp. 1-9 (1999) 
8. Olds, B., Miller, R., Pavelich, M.: Measuring the Intellectual Development of Engineering Students Using Intelligent Assessment Software. In: Proceedings of the International Conference on Engineering Education, Taipei, Taiwan, August 14-18 (2000)

9. Vrettaros, J., Vouros, G., Drigas, A.: Development of a Diagnostic System of Taxonomies Using Fuzzy Logic - Case SOLO (useful for e-learning system). In: Proceedings of 5th WSEAS International Conference on Automation \& Information (ICAI 2004), Venice, Italy, November 15-17 (2004); Selected and is included also in WSEAS Transactions on Information Science and Applications 1(6) (December 2004)

10. Zadeh, L.A.: Fuzzy Sets. Information and Control, 338-353 (1965)

11. Drigas, A.S., Vrettaros, J.: An Intelligent Tool for Building E-Learning Contend-Material Using Natural Language in Digital Libraries. In: Proceedings of WSEAS Int. Conf. on E-AVTIVITIES (E-AVTIVITIES 2004), Rethymno, Crete, Greece, October 24-26 (2004); Selected and is included also in WSEAS Transactions on Information Science and Applications 5(1) (November 2004)

12. Weon, S., Kim, J.: Learning achievement evaluation strategy using fuzzy membership function. In: Proceedings of the 31st ASEE/IEEE frontiers in education conference, Reno, NV, vol. 1, pp. 19-24 (2001)

13. McAlister, M., Wermter, S.: Rule Generation from Neural Networks for Student Assessment. In: Proceedings of the International Joint Conference on Neural Networks, Washington, USA (July 1999)

14. Al-Hammadi, A.S., Milne, R.H.: A Neuro-Fuzzy Classification Approach To the Assessment of Student Performance. In: IEEE International Conference on Fuzzy Systems, July 2004, vol. 2, pp. 837-841 (2004)

15. Homsi, M., Lutfi, R., Rosa, M.C., Barakat, G.: Student modeling using NN - HMM for EFL course. In: 3rd International Conference on Information and Communication Technologies: From Theory to Applications, ICTTA 2008, April 7-11, pp. 1-6 (2008)

16. Shen, R., Tang, Y., Zhang, T.: The Intelligent Assessment System in Web_based Distance Learning Education. In: 31st ASEE/IEEE Frontiers in Education Conference (2001)

17. Othman, M., Ku-Mahamud, K.R., Abu Bakar, A.: Fuzzy evaluation method using fuzzy rule approach in multicriteria analysis. Yugoslav Journal of Operations Research 18(1), 95-107 (2008)

18. de Arriaga, F., El Alami, M., Arriaga, A.: Evaluation of Fuzzy Intelligent Learning Systems. In: Méndez-Vilas, A., et al. (eds.) Recent Research Develoments in Learning Technologies, Formatex (2005)

19. Kasabov, N.K., Kim, J.S., Gray, A.R., Watts, M.J.: FuNN - A Fuzzy Neural Network Architecture for Adaptive Learning and Knowledge Acquisition, Technical Report, Department of Information Science, University of Otago, Dunedin, New Zealand (1997)

20. Nykänen, O.: Inducing Fuzzy Models for Student Classification. Educational Technology \& Society 9(2), 223-234 (2006)

21. Frias-Martinez, E., Magoulas, G.D., Chen, S.Y., Macredie, R.D.: Modeling Human Behavior in User-Adaptive Systems: Recent Advances Using Soft Computing Technique. Expert Systems with Applications 29(2) (2005)

22. Lane, H.C.: Intelligent Tutoring Systems: Prospects for Guided Practice and Efficient Learning. Whitepaper for the Army's Science of Learning Workshop, Hampton, VA, August 1-3 (2006)

23. Brusilovsky, P., Peylo, C.: Adaptive and Intelligent Web - Based Educational Systems. International Journal of Artificial Intelligence in Education 13, 156-169 (2003) 
24. Al Hamadi, A.S., Milne, R.H.: A neuro - fuzzy approach for student performance modeling. In: Proceedings of the 2003 10th IEEE International Conference on Electronics, Circuits and Systems, ICECS 2003, vol. 3, pp. 1078-1081 (2003)

25. Baylor, A.L.: Intelligent agents as cognitive tools for education. Educational Technology 39(2), 36-40 (1999)

26. Alimisis, D., Moro, M., Arlegui, J., Pina, A., Frangou, S., Papanikolaou, K.: Robotics \& Constructivism in Education: the TERECoP project (2007)

27. Brusilovsky, P., Eklund, J.: A Study of User Model Based Link Annotation in Educational Hypermedia. Journal of Universal Computer Science 4(4), 429-448 (1998)

28. Ma, J., Zhou, D.: Fuzzy set approach to the assessment of student-centered learning. IEEE Trans. Educ. 43, 237-241 (2000)

29. Ali, M.S., Ghatol, A.A.: An Adaptive Neuro Fuzzy Inference System For Student Modeling. In: Web-Based Intelligent Tutoring Systems (2004)

30. Sevarac, Z.: Neuro Fuzzy Reasoner for Student Modeling. In: Proceedings of the Sixth International Conference on Advanced Learning Technologies, pp. 740-744 (2006)

31. Salleh, N.S.M., Jais, J., Mazalan, L., Ismail, R., Yussof, S., Ahmad, A., Anuar, A., Mohamad, D.: Sign Language to Voice Recognition: Hand Detection Techniques for Vision-Based Approach. In: Uniten Student Conference on Research and Development (SCOReD), May 14-15 (2007)

32. Hawkes, L.W., Derry, S.J., Rundensteiner, E.A.: Individualized tutoring using an intelligent fuzzy temporal relational database. International Journal of Man-Machines Studies 33, 409-429 (1990)

33. Siddique, M.N.H., Tokhi, M.: Training Neural Networks: Backpropagation vs. Genetic Algorithms. In: Proceedings of the IEEE International Joint Conference on Neural Networks, vol. 4, pp. 2673-2678 (2001)

34. Ma, J.: Group decision support system for assessment of problem-based learning. IEEE Trans. Educ. 39, 388-393 (1996)

35. Zhou, D., Ma, J., Kwok, R.C.W., Tian, Q.: Group decision support system for project assessment based on fuzzy set theory. Presented at the Proc. 32nd Hawaii Int. Conf. System Sciences (HICSS-32), Honolulu, HI (January 1999)

36. Kwok, R., Ma, J.: Use of group support system for collaborative assessment. Comput. Educ. Int. J. 32, 109-125 (1999)

37. VanLhen, K.: Student Modeling. In: Polson, M.C., Richardson, J.J., Lea (eds.) Foundations of Intelligent Tutoring Systems, Hove \& London (1988)

38. Biswas, R.: An application of fuzzy sets in students' evaluation. Fuzzy Sets Syst. 74(2), 187-194 (1995)

39. Chen, S.M., Lee, C.H.: New methods for students' evaluating using fuzzy sets. Fuzzy Sets Syst. 104(2), 209-218 (1999)

40. Liao, S.-H.: Expert system methodologies and applications - a decade review from 1995 to 2004. Expert Syst. Appl. 28(1), 93-103 (2005)

41. Drigas, A., Vrettaros, J., Kouremenos, D.: Tele education and e-learning services for teaching English as a second language to Deaf People, whose first language is the Sign Language. WSEAS Transactions on Information Science and Applications 1(3) (September 2004)

42. Drigas, A.S., Vrettaros, J., Stavrou, L., Kouremenos, D.: Elearning Environment for Deaf people in the E-Commerce and New Technologies Sector. In: 6th WSEAS International Conference on EACTIVITIES, Rethymno (October 20, 2004)

43. Brusilovsky, P.: Methods and Techniques of Adaptive Hypermedia. User Modeling and User-Adapted Interaction, vol. 6, pp. 87-129. Kluwer Academic Publ., Netherlands (1996) 